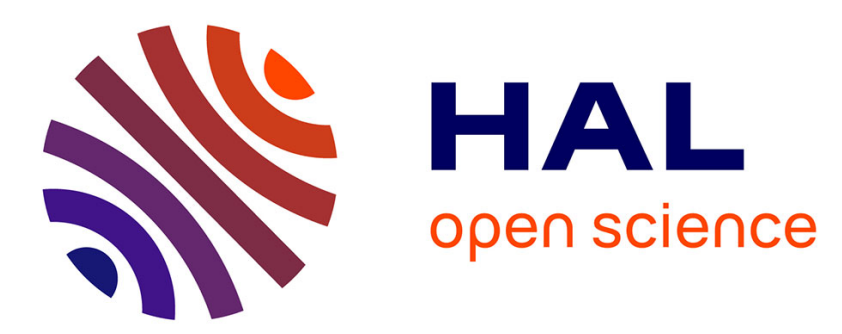

\title{
Estimating level effects in diffusion of a new technology: barcode scanning at the checkout counter
}

\author{
Jonathan Beck, Michal Grajek, Christian Wey
}

\section{To cite this version:}

Jonathan Beck, Michal Grajek, Christian Wey. Estimating level effects in diffusion of a new technology: barcode scanning at the checkout counter. Applied Economics, 2009, 43 (14), pp.1737. $10.1080 / 00036840802600624$. hal-00616884

\section{HAL Id: hal-00616884 \\ https://hal.science/hal-00616884}

Submitted on 25 Aug 2011

HAL is a multi-disciplinary open access archive for the deposit and dissemination of scientific research documents, whether they are published or not. The documents may come from teaching and research institutions in France or abroad, or from public or private research centers.
L'archive ouverte pluridisciplinaire HAL, est destinée au dépôt et à la diffusion de documents scientifiques de niveau recherche, publiés ou non, émanant des établissements d'enseignement et de recherche français ou étrangers, des laboratoires publics ou privés. 


\title{
Estimating level effects in diffusion of a new technology: barcode scanning at the checkout counter
}

\author{
Jonathan Beck ${ }^{a, *}$
}

\author{
Michal Grajek ${ }^{b}$
}

Christian Wey $^{c}$

August 2008

\begin{abstract}
Cross-country or cross-industry studies of technology diffusion typically estimate how independent factors affect diffusion speed or timing, often based on a two-stage approach. In many applications, however, countries (industries) differ most in the saturation level of diffusion. In a single-stage econometric approach to a standard diffusion model, we therefore estimate how the saturation level covaries with independent factors. In our application to diffusion of an important retail information technology, we focus on the competitive effect of hypermarkets (superstores). We also find standard scale, income and labor substitution effects.
\end{abstract}

JEL classification: L5, L81, O33.

Keywords: diffusion; information technology; retail competition.

Affiliations: ${ }^{a}$ Ludwig-Maximilians-Universität München, ${ }^{b}$ European School of Management and Technology (ESMT), ${ }^{c}$ Deutsches Institut für Wirtschaftsforschung (DIW), Technische Universität Berlin and CEPR, London.

\footnotetext{
*Corresponding author (beck@bwl.lmu.de; mail: Institute for Communication Economics, Munich School of Management, Schackstr. 4/III, 80539 Munich, Germany). Thanks to Joe Clougherty, Lapo Filistrucchi, Oz Shy, Irina Suleymanova and participants at the EEA conference in Vienna, the EARIE conference in Porto, the 5th ZEW Conference on the Economics of ICT in Mannheim, the BDPEMS workshop, the InterVal yearly meeting and the WZB seminar for comments and helpful discussions. Anna Kälberer and Kemal Azun provided able research assistance. Financial support from the German Federal Ministry of Education and Research, project InterVal - Internet and value chains (01AK702A), is gratefully acknowledged. The authors are responsible for all remaining errors.
} 


\section{Introduction}

Following the seminal work by Griliches (1957), cross-country or cross-industry studies of technology diffusion typically assess how diffusion speed or timing of a particular technology covaries with independent factors. The corresponding assumption is that the ceiling or saturation level of technology diffusion, which measures long-run technology usage, is invariant across time. While this assumption seems innocuous for technologies heading towards $100 \%$ penetration, such as Griliches' hybrid corn or, more recently, mobile telephony (Gruber and Verboven, 2001), it can be restrictive in other applications. In fact, Griliches (1957, p. 520) notes that "ceilings are not necessarily constant over time", and in a reply to late comments on his work he further states that he "would now use a model with an endogenous and shifting ceiling parameter", which the state of econometric art had prohibited earlier (Griliches, 1980, p. 1463).

To our knowledge, however, only few studies of technology diffusion have so far implemented this approach - despite the fact that cross-country level differences are considerable for many technologies (Comin, Hobijn and Rovito, 2006; Caselli and Coleman, 2001). ${ }^{1}$ The application presented in this paper is an exemplary case for endogenous saturation levels. In particular, we analyze newly compiled cross-country data on the diffusion of checkout barcode scanners in retailing, an information technology (IT) important also for other industries. The countries under consideration differ most in the long-run level of IT diffusion, less in timing or speed. We thus follow Griliches' recommendation to modify the standard diffusion model and estimate how independent factors affect the saturation level of diffusion. Particular focus is on the role of retail competition, namely in the form of hypermarkets.

In addition to a methodological point, this paper therefore has an interesting empirical contribution. In the context of our application, recent productivity studies attribute large post-1995 productivity gains in the United States to increased IT usage mainly in the distribution sector (Ark, McGuckin and Spiegelman, 2005; Stiroh, 2002). Most European countries, however, have not experienced such manifested developments in retail IT diffusion or productivity. Cette, Lopez and Noual (2005), for instance, attribute the IT

\footnotetext{
${ }^{1}$ A notable example are Liikanen, Stoneman and Toivanen (2004), who study intergenerational effects in the diffusion of mobile phones. Whereas Comin, Hobijn and Rovito (2006) look at direct data on a large number of technologies and countries, Caselli and Coleman (2001) study the diffusion of computers using imports of computing equipment as an indirect measure.
} 
diffusion gap between Europe and the U.S. to structural differences between the countries. An often-stated worry is that this may be due to excessive retail regulation and consequently less intensive retail competition in Europe (Scarpetta, Hemmings, Tressel and Woo, 2002, for example). Empirical results in this respect are of interest not only to understand historical developments, but also because the next generation of retail IT radio frequency identification (RFID) - is on the verge of mass market introduction. Yet, empirical studies of the relationship between retail regulation and competition on the one hand and retail innovation and productivity on the other hand are rare, despite a rich parallel literature on the link between retail regulation and employment (Bertrand and Kramarz, 2002). More comprehensive studies of product market competition and innovation typically restrict attention to manufacturing industries (Aghion et al., 2005, for example). ${ }^{2}$

In what follows, we first discuss previous approaches to aggregate data on technology diffusion and propose to incorporate a time-varying saturation level. We then present our retail industry data and results from country-wise and pooled estimations (section 3). After a discussion of a number of robustness checks, section 4 offers some final remarks.

\section{Analytical framework}

Patterns of aggregate technology diffusion usually resemble a sigmoid shape. Most empirical studies thus follow Griliches (1957) and employ the logistic function as analytical tool, which captures the sigmoid shape through three easily interpretable parameters: ${ }^{3}$

$$
S_{t}=\frac{\gamma N_{t}}{1+\exp (-\beta(t-\tau))}
$$

where $S_{t}$ denotes the number of technology adopters at time $t$. Over time, $S_{t}$ converges to a ceiling or saturation level of adopters, which is a fraction $\gamma$ of the total population $N_{t}$. Timing and speed of this process are determined by parameters $\tau$ and $\beta$. Provided with

\footnotetext{
${ }^{2}$ Regarding the retail sector, we are only aware of studies based on firm-level data, for example Foster, Haltiwanger and Krizan (2002) and Levin, Levin and Meisel (1987,1992). Although rich in various aspects, firm-level data typically lack variation in the regulatory environment and hence provide little opportunity to examine policy issues.

${ }^{3}$ With micro-level data, discrete choice and hazard rate models are commonly used; for example, see Karshenas and Stoneman (1993), Åstebro (2004) and the references therein. For a review see Hall and Khan (2003).
} 
data on $S_{t}$ and $N_{t}$ and assuming that the three parameters are constant over time, they may be estimated, for example, by non-linear least squares (NLS) under the assumption of an additive error term. ${ }^{4}$

Properties. For the moment, suppose that $\beta, \tau$ and $\gamma$ are time-invariant. In that case, the function is symmetric: $S_{t}$ equals half of its saturation level at the curve's inflection point $\tau$. At date $t=\tau$, the growth rate of the number of adopters is no longer increasing. Hence, $\tau$ is a measure for the timing of adoption - it shifts the S-curve forwards or backwards on the timeline.

Differentiating equation 1 with respect to time shows that coefficient $\beta$ is a measure for the speed of adoption. It gives the growth rate of $S_{t}$, relative to its distance to the saturation level, thereby causing the non-linear shape of the diffusion curve: $\frac{\mathrm{d} S_{t}}{\mathrm{~d} t} \frac{1}{S_{t}}=$ $\beta \frac{\gamma N_{t}-S_{t}}{\gamma N_{t}}$. The maximum growth rate of $S_{t}$ is thus $\frac{\beta}{2}$ (attained at time $\tau$ ). ${ }^{5}$

Fitness. One may wonder whether the logistic is the right functional form. Based on a large set of data covering numerous countries and technologies, Comin, Hobijn and Rovito (2006) argue that the logistic is not an appropriate functional form to describe the intensive margin in technology diffusion. The intensive margin measures the intensity at which a technology is used across time by its adopters. ${ }^{6}$ Most data including ours, however, measure the extensive margin (the number of adopters), for which the logistic seems appropriate. Moreover, Comin, Hobijn and Rovito (2006) note that their findings may be due to the standard assumption of a time-invariant ceiling. Other studies have criticized the symmetry of the logistic function and argued in favor of asymmetric functions such as the Gompertz (Dixon, 1980, for example). In general, and particularly in this paper, we prefer Zvi Griliches' position to emphasize data rather than functional form:

"Adding parameters to the curve itself or fiddling with the functional form is not an attractive alternative, in my opinion. What one gains in fit one loses in interpretability. Instead, I would now respecify the model so that the ceiling

\footnotetext{
3.3).

${ }^{4}$ Of course, the usual econometric suspects such as autocorrelation may have to be dealt with (see section

${ }^{5}$ Most studies, however, use another version of equation 1 , where $S_{t}=\gamma N_{t} /[1+\exp (-\alpha-\beta t)]$. Whereas the advantage of that version is that it lends itself more easily to log-linearization, its disadvantage is that $\alpha$ is erroneously interpreted as a timing indicator. Instead, $\alpha=-\beta \tau$ and hence 'timing' estimates for $\alpha$ resulting from the traditional version are strongly correlated with respective speed estimates for $\beta$.

${ }^{6}$ The intensive margin corresponding to our data would be the share of retail sales that go through scanner checkouts.
} 
is itself a function of economic variables that change over time."

(Griliches, 1980, p. 1463)

Adding independent variables. For his 1957 paper, Griliches basically estimated the three parameters of equation 1 separately for each of 31 U.S. states, and assessed how these estimates correlate with other variables across states. Most subsequent crosscountry or cross-industry studies employed a variation of this two-stage approach (see Comin, Hobijn and Rovito, 2006, for a recent example). ${ }^{7}$ In this paper, we follow Griliches later suggestion and incorporate independent variables directly into a single-stage crosscountry estimation of the logistic function

$$
S_{i t}=\frac{\left(\gamma_{i}+\mathbf{x}_{\mathbf{i t}}{ }^{\prime} \gamma^{x}\right) N_{i t}}{1+\exp \left(-\beta_{i}\left(t-\tau_{i}\right)\right)}+\epsilon_{i t}
$$

where $\mathbf{x}$ contains a number of independent variables, subscript $i$ indicates countries and $t$ indicates periods. The additive error term $\epsilon_{i t}$ allows us to estimate equation (2) by NLS.

The coefficients $\beta_{i}, \tau_{i}$ and $\gamma_{i}$ account for time-invariant country-specific effects as well as for time-invariant cross-country measurement differences. Hence, they serve a similar objective than fixed effects in a standard cross-country panel regression. In other words, we retain the full flexibility of a country-wise estimation of the logistic function but use equation 2 to ask whether the variables contained in $\mathbf{x}$ provide additional information regarding cross-country differences in the long-run diffusion level. Accordingly, $\gamma^{x}$ estimates the average marginal effect of variable $x$ on the country-specific saturation level.

Most theoretical studies of technology diffusion, in contrast, focus on explaining diffusion speed. In response, some empirical studies used an approach comparable to equation 2 but relating $\beta$ to independent variables (Gruber, 1998; Gruber and Verboven, 2001; Liikanen, Stoneman and Toivanen, 2004; Koski and Kretschmer, 2005; Lee and Cho, 2007, for example). Such an approach, however, neglects to explain the frequently found, considerable cross-country differences in $\gamma$. A common response to such findings - and in general to $\gamma$-estimates below 1 - is to assert that the population of potential adopters

\footnotetext{
${ }^{7}$ An alternative approach is a linear cross-country panel regression analysis, in which a potentially nonlinear diffusion pattern is partly accounted for by time dummies (Caselli and Coleman, 2001; Comin and Hobijn, 2004). The respective coefficients are typically assumed to be constant across countries, such that the added independent variables capture cross-country differences in both timing and saturation level of technology diffusion.
} 
$(N)$ is erroneously specified (Trajtenberg and Yitzhaki, 1989). Specification 2, instead, acknowledges both the inevitable imperfectness of measure $N$ and the time-invariant nature of the long-run diffusion level by allowing $\gamma$ to be smaller than 1 and subject to time-variant economic factors. To the best of our knowledge, only Liikanen, Stoneman and Toivanen (2004) model cross-country and time differences in the saturation level (albeit within a different functional form).

Finally, notice that this specification should be more robust in estimations. For example, estimation can encounter convergence problems when the non-linear function to be estimated is too complex. In contrast to the case when $\mathbf{x}$ enters the denominator of the logistic function through $\beta$ or $\tau$, here it enters the numerator. Equation 2 is thus more linear-like, which facilitates estimation.

\section{Application to a retail information technology}

Our application is the diffusion of first-generation checkout barcode scanners. The first retail outlet was equipped with a barcode scanner in 1974 in the United States (Nelson, 2001). In Europe, however, diffusion did not take off before the 1980s. Until 1997, the national member organizations of the European Article Numbering Association (EAN) collected data on the number of retail outlets with scanner installations. These data are published for the years 1981 to 1996 in the yearly reports of the EAN. ${ }^{8}$ Unfortunately, we were unable to obtain respective U.S. data beyond that presented in table 1; we also lack U.S. data for some of the independent variables. We therefore do not include the U.S. in our econometric analysis. Figure 1 in the appendix plots the dependent variable for the U.K., France, Germany, and Italy.

From today's perspective, the figures in table 1 - but also those for some European countries presented below - appear to exhibit implausibly low adoption rates. After all, our daily shopping experience suggests that barcode scanners are ubiquitous. Yet, notice that we consider not only grocery retailing but the whole retail sector; which includes types of retailers that typically do not use barcode scanners (flower shops, repair shops or bakeries, for example). Furthermore, the EAN data reliably covers only fixed scanners in

\footnotetext{
${ }^{8}$ The earliest EAN report available (at www.ean-int.org) is the 1983 report, which also gives figures for 1981 and 1982 for most countries (or indicates that there were no scanning stores before 1983 in a particular country).
} 
Table 1: Diffusion of barcode scanning in the U.S., 1974-1984

\begin{tabular}{|c|c|c|c|c|}
\hline Year & $\begin{array}{r}\text { Scanning stores }{ }^{a} \\
\text { (number) }\end{array}$ & $\begin{array}{l}\text { Outlets with } \\
\text { payroll }^{b}\end{array}$ & $\begin{array}{r}\text { Scanning stores } \\
(\%)\end{array}$ & $\begin{array}{r}\text { Scanning food } \\
\text { stores }(\%)^{c}\end{array}$ \\
\hline 1974 & 6 & 726940 & $<.00001$ & \\
\hline 1976 & 97 & 744780 & $<.00001$ & \\
\hline 1980 & 2483 & 738100 & .00003 & \\
\hline 1982 & 5902 & 784700 & .00008 & \\
\hline 1984 & 9278 & 831300 & .00011 & \\
\hline 1988 & & & & 59.7 \\
\hline 1989 & & & & 57.7 \\
\hline \multicolumn{5}{|c|}{$\begin{array}{l}\text { Sources: } \\
\text { Euromonitor (1986, based on trade magazine Chain Store Age); } \\
{ }^{a} \text { Bureau of the Census }(1978, \text { and later issues); } \\
{ }^{c} \text { Food Marketing Institute }(1989,1990) .\end{array}$} \\
\hline
\end{tabular}

checkout counters. Many smaller retailers now work with hand-held or mobile barcode scanners, which did not took off before 1997. The apparent inconsistency between the saturation level of barcode scanning in our data and the one perceived today is then driven by the type of scanners we consider. At the same time, it limits the interpretation of our results to the first generation of fixed scanners.

Country-wise estimations. Table 2 presents estimates from separate country-wise NLS estimations of equation 1 . We also provide the estimations' $R^{2}$, yet only to compare fit across countries; high $R^{2}$ values are common in such non-linear models and not per se suggestive of a good specification (Trajtenberg and Yitzhaki, 1989). Given the limited number of observations, the results in table 2 should be treated with caution as merely descriptive statistics.

The number of outlets, $N_{i t}$, is counted in hundreds such that $\hat{\gamma}_{i}$ indicates the estimated saturation level as the percentage of stores with a checkout barcode scanner. Altogether, country-wise estimation results are in line with the productivity studies cited earlier. Cross-country differences seem to be most pronounced with respect to the saturation level of IT adoption as measured by $\hat{\gamma}_{i}$. For example, Austria is estimated to have about $24 \%$ of outlets with checkout barcode scanning in the long run but Italy only $1 \% .{ }^{9}$

\footnotetext{
${ }^{9}$ In contrast to the Italian case, we are rather surprised by the low estimated saturation level for Ireland, since Ireland's retail structure is more comparable to that of the U.K. (see table 6 in the appendix). As Ireland has developed strongly throughout the 1990s, we presume that our data cover only the very beginning of a corresponding diffusion process, which complicates estimation (Debecker and Modis, 1994). We return to this point below.
} 
Table 2: Coefficients from country-wise estimations ${ }^{a}$

\begin{tabular}{llllrr}
\hline Country & $\hat{\gamma}_{i}$ & $\hat{\beta}_{i}$ & $\hat{\tau}_{i}$ & Observations & $R^{2}$ \\
\hline Austria & $24.2^{*}(2.9)$ & $.50^{*}(.03)$ & $1994.0(.45)$ & 14 & .999 \\
Belgium & $16.0^{*}(1.9)$ & $.39(.02)$ & $1994.1(.57)$ & 12 & .999 \\
Denmark & $10.7(1.5)$ & $.42(.06)$ & $1992.1(.80)$ & 15 & .992 \\
France & $10.7(2.2)$ & $.41(.04)$ & $1994.4(.99)$ & 13 & .996 \\
Germany & $5.2^{*}(.2)$ & $.41(.02)$ & $1992.7^{*}(.24)$ & 15 & .999 \\
Ireland & $1.3^{*}(.1)$ & $.48(.03)$ & $1992.7^{*}(.31)$ & 16 & .998 \\
Italy & $1.1^{*}(.2)$ & $.45(.08)$ & $1992.0(.88)$ & 15 & .986 \\
Netherlands & $7.6(2.2)$ & $.31^{*}(.03)$ & $1994.8(1.7)$ & 14 & .997 \\
Spain & $3.9^{*}(1.6)$ & $.39(.08)$ & $1995.1(2.1)$ & 16 & .978 \\
United Kingdom & $15.4(3.4)$ & $.41(.04)$ & $1995.8(1.0)$ & 16 & .995 \\
\hline Cross-country average & 9.6 & .42 & 1993.8 & & \\
\hline
\end{tabular}

${ }^{a}$ Parameter estimates from country-wise NLS estimation of equation 1 (asymptotic standard errors in parentheses). Starred coefficients differ significantly from crosscountry average (95\% confidence level, F-test based on asymptotic standard errors).

Differences with respect to timing and speed of diffusion seem less pronounced. Only in two cases do estimates for $\beta_{i}$ and $\tau_{i}$ differ significantly from the cross-country average of .42 (which implies a growth rate in the number of barcode scanning stores of $21 \%$ around year 1994).

Yet, the estimated absolute values for $\gamma$ should not be taken too literally: first, measurement of $N_{i t}$ may differ across countries; for example, for some countries it may include mobile outlets (street traders), for others not. ${ }^{10}$ Second, and more importantly, differences in adoption patterns may arise from differences in population heterogeneity, that is, underlying retail market structures. The Italian retail market, for example, is highly segmented, with many small but specialized retailers selling goods that in other countries are sold jointly by larger retailers. Like most other countries - but eventually to a different degree - Italy experienced considerable changes in retail market structure in the last decades. Such changes in heterogeneity not necessarily affect the absolute value of $N_{i t}$, but rather its composition and consequently long-run levels of IT diffusion estimated by $\hat{\gamma}$.

We conclude that our application constitutes a well-suited case for an econometric approach to relate differences in $\gamma$ to independent variables that capture retail hetero-

\footnotetext{
${ }^{10}$ Measurement differences do not appear to be substantial, however: we obtain similar cross-country differences if we relate the number of barcode scanning stores to population instead of the total number of outlets (see section 3.3).
} 
geneity as well as other economic factors. With the country-specific coefficients $\gamma_{i}$ in equation 2, the pooled estimation accounts for time-invariant cross-country as well as potential measurement differences in estimating the marginal effect of independent variables on long-run diffusion.

\subsection{Independent variables}

A complicating issue for empirical studies of the retail sector is that publicly available information is scarce, even on the country-year level. Although we compile data from various sources, a number of limitations make us restrict attention to 10 European countries. Table 3 describes the corresponding set of independent variables (table 6 in the appendix gives more detailed summary statistics).

Table 3: Description of independent variables

\begin{tabular}{cllc}
\hline Label & Description & Source & $\begin{array}{c}\text { Cross-country mean } \\
1981 / 1996\end{array}$ \\
\hline OUT & $\begin{array}{l}\text { No. of retail outlets } \\
\text { (per mn. inhabitants) }\end{array}$ & $\begin{array}{l}\text { Euromonitor, } \\
\text { World Bank }\end{array}$ & $9361.8 / 7952.4$ \\
HYP & $\begin{array}{l}\text { No. of hypermarkets } \\
\text { (per mn. inhabitants) }\end{array}$ & $\begin{array}{l}\text { Euromonitor, } \\
\text { World Bank }\end{array}$ & $6.8 / 13.3$ \\
EPL & $\begin{array}{l}\text { OECD indicator of strictness of } \\
\text { employment protection legislation }\end{array}$ & OECD & $2.5 / 2.2$ \\
WAGE & $\begin{array}{l}\text { Retail hourly real wage } \\
\text { (index 1995=100) }\end{array}$ & $\begin{array}{l}\text { GGDC, } \\
\text { World Bank }\end{array}$ & $74.2 / 101.1$ \\
GDP & $\begin{array}{l}\text { Per capita real GDP } \\
\text { (index 1995=100) } \\
\text { Retail sales volume } \\
\text { (index 1995=100) }\end{array}$ & World Bank & $74.8 / 102.1$ \\
& & OECD, & $85.7 / 101.3$ \\
\hline
\end{tabular}

Data on the total number of retail outlets (OUT) and the number of hypermarkets $(H Y P)$ are from various issues of "Retail trade international", a publication by the market research firm Euromonitor. The most recent issue is Euromonitor (2002). The source for GDP and population figures is the World Bank (2003). As a measure for the severity of labor market restrictions, we use version 1 of the revised OECD indicator of the strictness of employment protection legislation (OECD, 2004). The indicator of retail sales volume $(V O L)$ is also from the OECD. ${ }^{11}$ The retail WAGE index is constructed using data from the

\footnotetext{
${ }^{11}$ For Italy and Spain, this indicator does not cover the whole sample period. For these two countries, we therefore constructed a comparable indicator based on Euromonitor and GGDC data (see Beck, Grajek and Wey, 2005, for more details).
} 
60-Industry Database of the Groningen Growth and Development Centre (GGDC). Some missing values had to be replaced with univariate procedures (the appendix in Beck, Grajek and Wey, 2005, gives a detailed list of all data manipulations). We were unable to obtain information on a number of factors that may also be important in our analysis, such as prices for scanning equipment, opening hours, the importance of multinational firms, or average store size. As long as these omitted factors are relatively time-invariant or equal for the countries in our sample, they are accounted for by the country-specific estimates for $\gamma_{i}$.

Predicted effects. When deciding about the adoption of a new technology, a firm typically compares costs and benefits of adoption at a given point in time (Hall and Khan, 2003). In our case, the installation of a barcode scanner represents a major capital investment that basically enables a retailer to check out more retail items in less labor time. ${ }^{12}$ Following the discussion by Levin, Levin and Meisel $(1987,1992)$, our independent variables capture a number of factors that can make barcode scanning more or less valuable in different countries. ${ }^{13}$ First, the expected financial returns to such a capital investment depend on future market conditions. Since return-on-investment is quicker in growing markets, retailers there will adopt more intensely than retailers in stagnating or contracting markets. In addition, barcode scanning may introduce or increase economies of scale in retailing. In both cases, we expect adoption intensity to increase with market volume $(V O L)$. Second, barcode scanning is likely to reduce customer waiting time at the checkout. Customers in high-income countries have a higher opportunity cost of waiting. Using per-capita GDP as a measure of income, we expect diffusion of barcode scanning to increase with GDP. In this interpretation, barcode scanning is a product-enhancing innovation: it increases the quality of retailing for the customer.

Another more classical interpretation regards barcode scanning as a process-enhancing innovation. Most prominently, barcode scanning may be a labor-saving technology that reduces total labor demand. In addition to this classic capital-labor substitution effect, barcode scanning may allow retailers to substitute unskilled for costly skilled labor. Clerks at scanner checkouts need neither know prices nor be able to type quickly. In both cases

\footnotetext{
${ }^{12}$ Clearly, barcode scanning also facilitates other potentially productivity-enhancing practices, e.g. sophisticated logistics systems ('efficient consumer response', 'category management'); but these systems did not develop before the mid-1990s and still seem to represent "untapped potential" (Haberman, 2001).

${ }^{13}$ Levin, Levin and Meisel $(1987,1992)$ study the adoption of barcode scanning in U.S. retailing. They analyse firm-specific data relating to the early years of the technology (1974-1985).
} 
of substitution, we thus expect countries with rising retail wages (WAGE) to invest more in a labor-saving technology such as barcode scanning. In contrast, strict employment protection legislation $(E P L)$ may prohibit retailers from substituting barcode scanners for labor as extensively as the technology might allow (IMF, 2001). On the other hand, evidence from India suggests that labor regulation may generally promote IT usage by retailers (Amin, 2007).

Retail competition. Our particular focus, however, is on the role of competition. Fragmented retail structures are most often the direct result of entry restrictions. In general, these restrictions tend to favor small retailing in downtown areas against large scale retail formats as exemplified by Wal-Mart. Most prominently, planning and construction restrictions have been used in all European countries to ban large retailing formation; e.g., by not granting construction permissions or by limiting store size (Bertrand and Kramarz, 2002). Planning and construction restrictions have been eased first in the U.K. by the Thatcher government and later in other European countries as well.

With these developments, hypermarkets have become an integral element of most retail markets. According to the standard definition, hypermarkets have a minimum size of 2,500 square meters, and sell both food and non-food items. ${ }^{14}$ Hypermarkets often locate in peripheral areas which are easily accessible by car; in the U.S. similar stores are often called "superstores". In most European countries, the hypermarket retail format emerged in the 1970s and 1980s. ${ }^{15}$ In this paper, we use the number of hypermarkets per capita $(H Y P)$ as an inverse indicator of entry restrictions: an increasing number of hypermarkets is a result of less restrictive entry regulations, and hence a proxy for increasing competitive intensity due to regulatory change. Moreover, hypermarkets may reflect competitive intensity on other grounds. They can be regarded as low-cost competitors who exploit the cost benefits of out-of-town locations, sophisticated logistics, and economies of scale (Basker, 2005). One may also view retail competition as competition of retail channels or formats (Smith and Hay, 2005). In that sense, the emergence and growth of a new format, like the hypermarket, intensifies retail competition as such.

\footnotetext{
${ }^{14}$ Two countries in our sample - Germany and Denmark - apply a slightly broader hypermarket definition which includes large supermarkets with a floor space between 1,500 and 2,500 square meters. In our pooled estimation below, we allow for a different hypermarket effect for these two countries.

${ }^{15}$ Carrefour, one of the world's largest retailers, claims to have invented the concept. It opened its first hypermarket in 1963 near Paris, "with a floor space of 2,500 square meters, 12 checkouts and 400 parking spaces" (see www.carrefour.com/english/groupecarrefour/annees60.jsp).
} 
In our working paper (Beck, Grajek and Wey, 2005), we present precursory evidence supporting this view. Namely, the appearance of hypermarkets seems to lead to increased market exit rates of other retail outlets. With regard to IT diffusion, such hypermarket competition can have two - potentially independent - effects. ${ }^{16}$ On the one hand, since hypermarket entry seems to induce exit of other retailers, this may entail a selection effect: if the exiting retailers predominantly belong to the group of (long-run) IT adopters, hypermarket competition reduces the share of adopters in the remaining retailers. On the other hand, it can have an encouragement effect on the remaining retailers, for example, when hypermarket entry leads former non-adopters to become adopters in the long run. If hypermarkets are more likely to adopt, this gives them a competitive advantage, thereby inducing competitors to also adopt. With industry-level data on IT diffusion, however, we can only identify the joint impact of the selection and the encouragement effect. This joint effect can be positive or negative.

For an illustration, consider a simple numerical example. Imagine a country with 100 retailers, 50 of which are potential adopters of barcode scanning. There are no hypermarkets yet. While barcode scanning diffuses, one of the retailers decides to restructure and become a hypermarket, which drives 10 other retailers out of business. Depending on whether these 10 quitting retailers were potential adopters or not, the selection effect of the hypermarket on long-run diffusion can be negative or positive. In case all quitters were non-adopters, the long-run diffusion level increases from .5 to .56 (50 out of 90). In case they had been (potential) adopters, it reduces to .44 (40 out of 90). Moreover, an encouragement effect of increased competition could be that some of the previous non-adopters become potential adopters of barcode scanning, which raises its long-run diffusion level.

Bivariate correlations. For a first idea on how the discussed factors might relate to cross-country differences in barcode scanning, we first follow the standard two-stage approach and assess how the countries' separately estimated saturation levels correlate with country-specific trends of the proposed variables. Table 4 lists the correlation coefficients.

With one exception, all bivariate correlation coefficients are in line with the above theoretical expectations. The negative hypermarket effect is surprisingly clear in the data: between 1981 and 1996, 5 out of 10 countries have an average yearly growth in

\footnotetext{
${ }^{16}$ In section 3.3, we argue that reverse causality or endogeneity are not affecting the observed relationship between hypermarkets and IT diffusion.
} 
Table 4: Bivariate correlations between $\hat{\gamma}_{i}$ and independent variables ${ }^{a}$

\begin{tabular}{|c|c|c|c|c|c|}
\hline \multicolumn{6}{|c|}{ Correlation between } \\
\hline & & country-sp & ecific trend & efficient fo & \\
\hline & $\log (H Y P)$ & $\log (E P L)$ & $\log (W A G E)$ & $\log (G D P)$ & $\log (V O L)$ \\
\hline and $\hat{\gamma}_{i}$ & -.526 & .512 & .501 & .015 & .581 \\
\hline \multicolumn{6}{|c|}{$\begin{array}{l}{ }^{a} \text { Based on nine observations (one per country, excluding Ireland): } \\
\hat{\gamma}_{i} \text { and trend coefficient from country-wise regression of } \log \left(x_{i t}\right) \text { on } t \text {. } \\
\text { Trend coefficients are significant with } 95 \% \text { confidence for all countries } \\
\text { and variables except for two countries with variable VOL. }\end{array}$} \\
\hline
\end{tabular}

the per-capita number of hypermarkets below 3\% - as proxied by a trend coefficient in a regression of $\log (H Y P)$. The average estimated saturation level is $12.7 \%$ for these countries (Austria, Belgium, Denmark, Germany, Netherlands), but only 6.5\% for the other five countries that had stronger hypermarket growth.

In addition, table 4 suggests that estimated saturation levels are higher in countries with larger growth of GDP, retail sales volume, retail wages and employment protection, and lower in countries with larger hypermarket growth. ${ }^{17}$ The observed positive correlation between employment protection and the estimated saturation levels may be due to a statistical limitation of these bivariate correlation measures. They account neither for time-invariant country-specific effects in $\gamma$ - which may be affected by measurement differences - nor for year-to-year and multivariate correlations. For example, EPL may be positively correlated with WAGE or another measure that is itself positively correlated with the estimated saturation levels. This correlation may be the dominating factor in a bivariate correlation analysis that just considers EPL and the saturation level.

\subsection{Pooled estimation}

In order to account for such multivariate effects as well as country-specific effects, we pool countries and estimate a joint logistic function (equation 2) ${ }^{18}$ Estimations based on the full sample, however, exhibited convergence problems and led to large and unstable estimates for Ireland's country-specific coefficients $\gamma_{i}, \beta_{i}$ and $\tau_{i}$ (unreported). We actu-

\footnotetext{
${ }^{17}$ When we include Ireland in calculating these correlation coefficients, only the coefficient for GDP changes qualitatively, resulting from Ireland's combination of strong GDP growth with a low $\gamma$-estimate.

${ }^{18}$ We use the estimates from the country-wise regressions as initial values for country-specific effects. For the independent variables' coefficients, we set initial values equal to 0 .
} 
ally find this result reaffirming in two respects. First, it seems to confirm the suspicion that the data for Ireland do not cover a sufficiently large portion of its diffusion of barcode scanning. Second, it suggests that the independent variables do contain additional information, since Ireland-specific estimates based on equation 1 (thus excluding $\mathbf{x}$ ) spuriously appeared stable. In what follows, we therefore present results excluding Ireland. The independent variables' coefficients are similar to estimates including Ireland, but convergence is smoother and all country-specific estimates are now stable.

The first column of Table 5 presents the results for our baseline specification (I), where $D$ is a dummy variable equal to one for Germany and Denmark to account for the different, somewhat broader hypermarket definition employed for these countries. In addition, we present results for two alternative specifications: in specifications II and III we exclude Germany; in specification III, we also exclude the variables EPL and $D^{*} H Y P$.

Table 5: Results for pooled estimations ${ }^{a}$

\begin{tabular}{|c|c|c|c|}
\hline \multicolumn{4}{|c|}{$\begin{array}{c}\text { Dependent variable: } \\
\text { Number of barcode scanning stores }\end{array}$} \\
\hline Specification & (I) & (II) & (III) \\
\hline HYP & $\begin{array}{r}-1.852^{*} \\
(.426)\end{array}$ & $\begin{array}{r}-1.744^{*} \\
(.408)\end{array}$ & $\begin{array}{r}-1.756^{*} \\
(.425)\end{array}$ \\
\hline$D^{*} H Y P$ & $\begin{array}{c}6.668^{*} \\
(2.505)\end{array}$ & $\begin{array}{r}1.837 \\
(2.154)\end{array}$ & \\
\hline$E P L$ & $\begin{array}{l}-1.333 \\
(2.287)\end{array}$ & $\begin{array}{r}-1.154 \\
(2.108)\end{array}$ & \\
\hline WAGE & $\begin{array}{r}.119^{*} \\
(.032)\end{array}$ & $\begin{array}{c}.123^{*} \\
(.031)\end{array}$ & $\begin{array}{l}.116^{*} \\
(.028)\end{array}$ \\
\hline$G D P$ & $\begin{array}{l}.394^{*} \\
(.069)\end{array}$ & $\begin{array}{l}.385^{*} \\
(.069)\end{array}$ & $\begin{array}{l}.408^{*} \\
(.061)\end{array}$ \\
\hline$V O L$ & $\begin{array}{l}.087 \S \\
(.048)\end{array}$ & $\begin{array}{r}.072 \\
(.047)\end{array}$ & $\begin{array}{r}.062 \\
(.047) \\
\end{array}$ \\
\hline Country excluded: & Ireland & $\begin{array}{l}\text { Ireland } \\
\text { Germany }\end{array}$ & $\begin{array}{r}\text { Ireland } \\
\text { Germany }\end{array}$ \\
\hline Time span (max.) & $1981-1996$ & 1981-1996 & $1981-1996$ \\
\hline Observations & 130 & 115 & 115 \\
\hline Adj. $R^{2}$ & .994 & .994 & .994 \\
\hline Root MSE & 494.6 & 504.2 & 499.4 \\
\hline
\end{tabular}


The effects for variables WAGE, GDP and VOL vary little across specifications and are for the most part significantly estimated. A 10-point increase in the retail wage index is associated with an estimated increase in the saturation percentage of barcode scanning stores by about 1.2 points on average. A 10-point increase in real GDP per capita and retail sales volume is associated with an estimated increase in the saturation level by about 4 and 1 points, respectively. All three results confirm initial expectations: First, investment in labor-saving retail IT can be interpreted as a reaction to changes in labor costs. Second, income, scale and returns-to-investment effects are important. Although the income effect measured by GDP seems more important than the scale effect measured by $V O L$, the effects are hard to distinguish empirically since the two variables are by definition correlated.

Consistent with the bivariate correlation found before, an increase in the number of hypermarkets by one per million inhabitants is associated with an estimated decrease in the saturation percentage of barcode scanning stores by almost 2 points. In aggregate terms, hypermarket competition therefore seems to reduce long-run IT usage in the retail sector. One interpretation of this result is that hypermarkets drive potential adopters out of the market (selection effect). The encouragement effect of hypermarkets on existing retailers to adopt barcode scanning is dominated - if existing at all - by the selection effect. The impact of the selection effect may be more important, because hypermarkets mainly compete with (and induce exit of) supermarkets - the main group of potential adopters - and less with other, smaller retailers.

Yet, the negative result appears to hold only for the standard hypermarket definition. In our baseline specification I, the estimate for the broader Danish/German definition is positive (-1.9+6.7). German figures, however, may be affected by exceptional efforts due to reunification: from 1989 onwards, East Germany experienced a catch-up in the number of retail outlets, many of which equipped with barcode scanners from the start. We therefore re-estimated the model excluding Germany and find that Germany indeed seems to be a special case. The estimated difference between the broad hypermarket definition and the standard one, now a Denmark-specific effect, is much lower and not significantly different from zero. Accordingly, an estimation which ignores different hypermarket definitions by excluding the interaction term $D^{*} H Y P$ (specification III) leads to an essentially unchanged hypermarket effect, as long as Germany remains excluded. In specification 
III we also exclude the EPL indicator, whose effect has the expected negative sign but is insignificant in all estimations. Other estimates remain largely the same.

\subsection{Robustness}

Autocorrelation can be an issue in estimating growth curves. Following a relatively straightforward testing procedure (Franses, 2002), in country-wise estimations we reject the null hypothesis of no autocorrelation against the alternative of AR(1) errors only for two countries (results available upon request). Yet, re-estimating a logistic function with an $\mathrm{AR}(1)$ error term for these countries leads to autocorrelation coefficients which are not significantly different from zero. We therefore retain the assumption of an $\mathrm{AR}(0)$ error term throughout the paper.

\section{Causal link between hypermarkets competition and the adoption of barcode scan-} ning. Although the first hypermarkets existed long before the introduction of barcode scanning, the technology's inherent scale effects lead hypermarkets to be among its first adopters. Moreover, the availability of this new technology may have driven the increase in average store size and may have eventually lead to more superstores or hypermarkets Holmes (2001). These two effects can potentially blur our interpretation that the coefficient on the hypermarket variable reflects a competition effect. First, because increased diffusion of scanners can merely reflect the emergence of new hypermarkets, which from the mid-19080s were almost certain to adopt the technology. Second, because the causality may as well go the other way around, i.e. from barcode scanning to the number of hypermarkets, leading to an endogeneity bias.

In order to tackle the first of this two problems, we subtract the number of hypermarkets from our dependent variable (as well as from the overall number of outlets, $N_{t}$ ) and re-estimate the model. By doing so, we estimate the effect of hypermarkets on diffusion of barcode scanning in the population of retail stores other than hypermarkets. The estimated coefficients remain virtually unchanged, suggesting that the hypermarketsక̌ adoptions do not drive our results. ${ }^{19}$

Whereas we do not have instrumental variables available to tackle the second problem, we can at least interpret the estimated negative correlation between the number of hypermarkets and the diffusion of barcode scanning as a lower bound (in absolute terms)

\footnotetext{
${ }^{19}$ The results are available from the authors upon request.
} 
of the competition effect. The hypothesis behind the reverse causality predicts a positive correlation between the two Holmes (2001). Thus, if the reverse causality biases our result, it is a downward bias (in absolute terms).

Data concerns. Another potential source of error are the implicit assumptions in our method to construct time series for the total number of retail outlets (see the data appendix in Beck, Grajek and Wey, 2005). We therefore estimated specifications I to III with a country's population (in millions) replacing the number of outlets in equation 2. For specifications II and III, all variables yield estimates with the same qualitative effects on the long-run number of barcode scanning stores per capita; except EPL, whose coefficients change sign but are again insignificant. Only for specification I, which includes the special case of Germany, some results differ (reported in Beck, Grajek and Wey, 2005). We infer that our results are not crucially affected by the data manipulations that were necessary to obtain a workable time series for the number of retail outlets.

Finally, our conclusions regarding the effect of EPL may be premature. Given missing values and other measurement problems associated with the OECD EPL index (Blanchard and Wolfers, 2000), there are reasons to doubt the validity of the indicator used. In order to cross-check results, we replaced the EPL indicator with country time series on the cumulative number of EPL reforms from the Social Reforms Database of the Fondazione Rodolfo DeBenedetti. When replaced for our initial EPL indicator in specification II, these variables also yield insignificant results (available upon request).

\section{Concluding remarks}

The first generation of checkout barcode scanners, a critical information technology in retailing, has diffused to different levels of long-run usage across European countries. Although similar observations hold for other technologies (Comin, Hobijn and Rovito, 2006), cross-country studies typically focus on explaining differences in diffusion speed or timing. In this paper, we propose a novel, single-stage econometric approach to relate long-run usage to independent factors within the standard reduced-form model of technology diffusion. This approach can be fruitful in other applications, particularly when heterogeneity in the population of technology adopters varies across observations. 
Results for our application are consistent with earlier studies. We find that, as expected, retail IT diffusion is more intense in countries with large and growing retail markets and economies. It is therefore not surprising that the United States, which experienced strong overall economic growth driven by a surge in consumer spending, are ahead of most European countries when it comes to IT diffusion in the retail sector and the resulting productivity gains throughout the 1990s. ${ }^{20}$ In line with standard theory, we also find that raising labor costs induce retailers to substitute barcode scanners for labor. In contrast, we do not find employment protection legislation to significantly impact retail IT diffusion. With respect to an upcoming "retail revolution" that relies on RFID technology, our results lead us to expect stronger RFID diffusion in countries that exhibit scale effects and upward wage pressure.

With regard to retail competition, our results suggest that the rise of hypermarkets reduces long-run retail IT diffusion. This effect, which is robust in a variety of specifications, has two potential explanations. First, hypermarket competition causes exit of potential IT adopters, namely smaller-sized supermarkets. Second, hypermarkets - which are most likely to adopt barcode scanning early - discourage subsequent adoptions of rival retail formats. Overall, these results suggest that liberalization of retail market entry and the associated emergence of hypermarkets deepens retail segmentation such that hypermarkets on the one hand and small down town retailing (including shopping mall retailing) prevail. In contrast, intermediate retail formats - in particular medium-sized supermarkets - are likely to suffer from market liberalization.

Yet, as we do not observe the intensive margin of retail IT diffusion, the productivity implications of our findings are not evident. Depending on how much retail volume goes through barcode scanning retailers, IT productivity may increase in relative terms with the emergence of hypermarkets, even though aggregate IT usage decreases at the extensive margin. Also, our data are not directly comparable to official measures of retail IT investments, since they count the number of barcode scanning stores, not the number of scanner installations. In our data, a smaller supermarket with, say, one scanner checkout has the same weight as a larger one with multiple scanner checkouts. Further research may include more countries and explanatory variables, for example measures of foreign

\footnotetext{
${ }^{20}$ Comparable OECD data for the retail volume indicator VOL indicate that, between 1990 and 2000, U.S. retail volume increased by about $67 \%$, whereas it increased by about $30 \%$ in the U.K. and by about $7 \%$ in France. In Germany, retail volume decreased by about 1\% between 1990 and 2000.
} 
direct investments in order to assess the role of large multinational retail firms in IT diffusion. Reviewing our efforts to put together the present dataset, we however fear such a task is more demanding than it seems at first sight. 


\section{A Appendix}

Figure 1: Number of barcode scanning stores (in \%, by country)

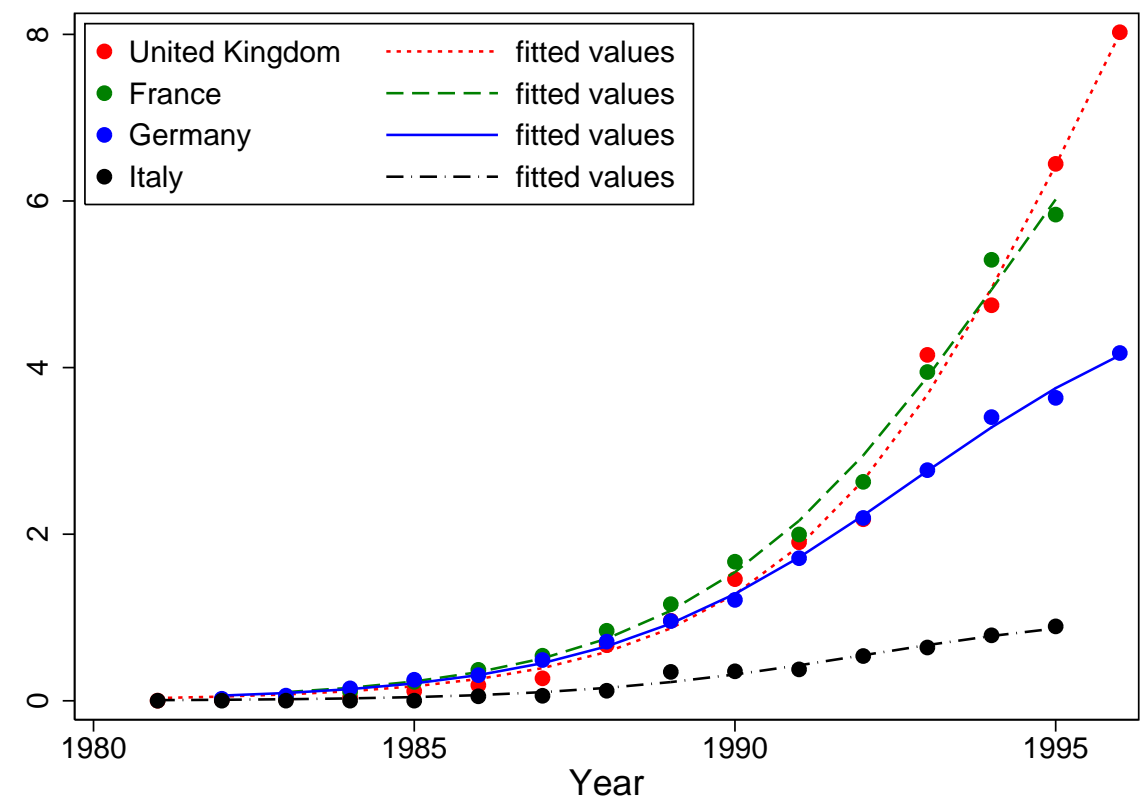


Table 6: Detailed summary of variables ${ }^{a}$

\begin{tabular}{|c|c|c|c|c|c|c|}
\hline Variable & OUT & HYP & $E P L$ & WAGE & GDP & $V O L$ \\
\hline \multicolumn{7}{|l|}{ Country } \\
\hline \multirow{2}{*}{ Austria } & 4762.5 & 29.9 & 2.2 & 87.9 & 94.0 & 95.2 \\
\hline & 356.2 & 15.6 & .2 & 45.3 & 37.6 & 31.8 \\
\hline \multirow[t]{2}{*}{ Belgium } & 4653.9 & 7.5 & 2.8 & 87.8 & 93.9 & 94.8 \\
\hline & 677.1 & 1.7 & .9 & 37.2 & 36.6 & 42.9 \\
\hline \multirow[t]{2}{*}{ Germany } & 4652.7 & 22.7 & 2.9 & 91.9 & 93.9 & 94.2 \\
\hline & 1937.8 & 11.6 & .9 & 37.0 & 31.5 & 27.2 \\
\hline \multirow[t]{2}{*}{ Denmark } & 6841.3 & 16.0 & 1.8 & 90.3 & 94.7 & 96.5 \\
\hline & 896.8 & 8.0 & .7 & 49.0 & 34.7 & 23.2 \\
\hline \multirow[t]{2}{*}{ Spain } & 20730.4 & 4.0 & 3.4 & 93.7 & 92.8 & 100.0 \\
\hline & 8573.0 & 6.6 & .8 & 43.1 & 46.0 & 27.3 \\
\hline \multirow[t]{2}{*}{ France } & 7159.5 & 15.3 & 2.8 & 93.6 & 95.5 & 98.4 \\
\hline & 2380.6 & 11.7 & .3 & 30.1 & 33.3 & 17.1 \\
\hline \multirow[t]{2}{*}{ Ireland } & 9177.1 & 5.3 & .9 & 92.7 & 91.1 & 100.0 \\
\hline & 707.9 & 13.1 & .1 & 68.3 & 99.0 & 74.5 \\
\hline \multirow[t]{2}{*}{ Italy } & 16139.8 & 3.9 & 3.6 & 94.7 & 93.4 & 99.0 \\
\hline & 6221.5 & 9.1 & 1.9 & 17.0 & 33.7 & 25.0 \\
\hline Nether- & 5469.4 & 2.4 & 2.5 & 95.8 & 94.3 & 101.5 \\
\hline lands & 652.0 & 1.5 & .6 & 24.0 & 40.2 & 25.0 \\
\hline United & 6740.1 & 3.4 & .5 & 91.0 & 93.1 & 93.6 \\
\hline Kingdom & 2564.8 & 4.6 & .2 & 40.8 & 44.8 & 61.5 \\
\hline \multicolumn{7}{|c|}{$\begin{array}{l}{ }^{a} \text { Country-specific means in the first line, in the second line } \\
\text { the difference between the maximum and the minimum } \\
\text { value observed in the respective series (range). } \\
\text { See table } 3 \text { for a description of the variables. }\end{array}$} \\
\hline
\end{tabular}




\section{References}

Aghion, Philippe, Nick Bloom, Richard Blundell, Rachel Griffith and Peter Howitt (2005), Competition and innovation: An inverted-U relationship, The Quarterly Journal of Economics, 120(2): 701-728.

Amin, Mohammad (2007), Are labor regulations driving computer usage in India's retail stores?, Policy Research Working Paper Series 4274, The World Bank.

Ark, Bart van, Robert H. McGuckin and Matthew Spiegelman (2005), The retail revolution - can Europe match U.S. productivity performance?, Report 1358, The Conference Board.

Åstebro, Thomas (2004), Sunk costs and the depth and probability of technology adoption, Journal of Industrial Economics, 52(3): 381-399.

Basker, Emek (2005), Selling a cheaper mousetrap: Wal-mart's effect on retail prices, Journal of Urban Economics, 58(2): 203-229.

Beck, Jonathan, Michal Grajek and Christian Wey (2005), Hypermarket competition and the diffusion of retail checkout barcode scanning, CEPR Discussion Paper 5386.

Bertrand, Marianne and Francis Kramarz (2002), Does entry regulation hinder job creation? Evidence from the French retail industry, The Quarterly Journal of Economics, 117(4): 1369-1413.

Blanchard, Olivier and Justin Wolfers (2000), The role of shocks and institutions in the rise of European unemployment: The aggregate evidence, The Economic Journal, 110(462): C1-33.

Bureau of the Census (1978), Statistical abstract of the United States: 1978, United States Bureau of the Census.

Caselli, Francesco and Wilbur J. Coleman (2001), Cross-country technology diffusion: The case of computers, The American Economic Review, 91(2): 328-335.

Cette, Gilbert, Jimmy Lopez and Pierre-Alexandre Noual (2005), Investment in ICTs: an empirical analysis, Applied Economics Letters, 12(5): 309-312. 
Comin, Diego and Bart Hobijn (2004), Cross-country technology adoption: Making the theories face the facts, Journal of Monetary Economics, 51(1): 39-83.

Comin, Diego, Bart Hobijn and Emilie Rovito (2006), Five facts you need to know about technology diffusion, NBER Working Paper.

Debecker, Alain and Theodore Modis (1994), Determination of the uncertainties in Scurve logistic fits, Technological Forecasting \& Social Change, 46: 153-173.

Dixon, Robert (1980), Hybrid corn revisited, Econometrica, 48(6): 1451-1461.

Euromonitor (1986), Retail Trade International: 1986 Edition, Euromonitor International Plc., London.

— (2002), Retail Trade International: 2002 Edition, Euromonitor International Plc., London.

Food Marketing Institute (1989), The food marketing industry speaks, 1989. Detailed tabulations, Food Marketing Institute.

- (1990), The food marketing industry speaks, 1990. Detailed tabulations, Food Marketing Institute.

Foster, Lucia, John Haltiwanger and C. J. Krizan (2002), The link between aggregate and micro productivity growth: Evidence from retail trade, NBER Working Paper Series, No. 9120.

Franses, Philip Hans (2002), Testing for residual autocorrelation in growth curve models, Technological Forecasting E Social Change, 69: 195-204.

Griliches, Zvi (1957), Hybrid corn: An exploration in the economics of technological change, Econometrica, 25(4): 501-522.

— (1980), Hybrid corn revisited: A reply, Econometrica, 48(6): 1463-1465.

Gruber, Harald (1998), The diffusion of innovations in protected industries: The textile industry, Applied Economics, 30(1): 77-83.

Gruber, Harald and Frank Verboven (2001), The diffusion of mobile telecommunications in the European Union, European Economic Review, 45: 577-588.

Haberman, Alan L. (ed.) (2001), Twenty-five years behind bars, Harvard University Press. 
Hall, Bronwyn H. and Beethika Khan (2003), Adoption of new technology, in: Jones, Derek C. (ed.), New Economy Handbook, Academic Press.

Holmes, Thomas J. (2001), Bar codes lead to frequent deliveries and superstores, RAND Journal of Economics, 32(4): 708-25.

IMF (2001), The Information Technology Revolution, chap. III, 105-144, International Monetary Fund.

Karshenas, Massoud and Paul L. Stoneman (1993), Rank, stock, order, and epidemic effects in the diffusion of new process technologies: An empirical model, RAND Journal of Economics, 24(4): 503-528.

Koski, Heli and Tobias Kretschmer (2005), Entry, standards and competition: Firm strategies and the diffusion of mobile telephony, Review of Industrial Organization, 26(1): 89113.

Lee, Minkyu and Youngsang Cho (2007), The diffusion of mobile telecommunications services in Korea, Applied Economics Letters, 14(7): 477-481.

Levin, Sharon G., Stanford L. Levin and John B. Meisel (1987), A dynamic analysis of the adoption of a new technology: the case of optical scanners, The Review of Economics and Statistics, 69: 12-17.

- (1992), Market structure, uncertainty, and intrafirm diffusion: The case of optical scanners in grocery stores, The Review of Economics and Statistics, 74(2): 345-50.

Liikanen, Jukka, Paul Stoneman and Otto Toivanen (2004), Intergenerational effects in the diffusion of new technology: the case of mobile phones, International Journal of Industrial Organization, 22(8-9): 1137-1154.

Nelson, John E. (2001), Scanning's silver celebration, in: Haberman (2001), 25-33.

OECD (2004), Employment outlook, Organisation for Economic Co-operation and Development.

Scarpetta, Stefano, Philip Hemmings, Thierry Tressel and Jaejoon Woo (2002), The role of policy and institutions for productivity and firm dynamics: evidence from micro and industry data, Tech. rep., OECD Economics Department. 
Smith, Howard and Donald Hay (2005), Streets, malls, and supermarkets, Journal of Economics \& Management Strategy, 14(1): 29-59.

Stiroh, Kevin J. (2002), Information technology and the U.S. productivity revival: What do the industry data say?, American Economic Review, 95(5): 1559-1576.

Trajtenberg, Manuel and Shlomo Yitzhaki (1989), The diffusion of innovations: A methodological reappraisal, Journal of Business \& Economic Statistics, 7(1): 35-47.

World Bank (2003), World development indicators CD-ROM, World Bank. 